\title{
From depressive symptoms to depressive disorders: the relevance of thresholds
}

\author{
José L. Ayuso-Mateos, Roberto Nuevo, Emese Verdes, Nirmala Naidoo and Somnath Chatterji
}

\section{Background}

Nosological boundaries for depressive disorders as well as the prevalence and impact of 'subsyndromal' depression remain unclear.

\section{Aims}

To examine the impact of subsyndromal depressive disorders on health status and to assess if depressive disorders lie on a continuum of severity.

\section{Method}

The sample was composed of randomly selected respondents from the general population in 68 countries from across the world participating in the World Health Organization's World Health Survey.

\section{Results}

The pattern of risk factors for depressive disorders was consistent across all types of depression (subsyndromal, brief depressive episode and depressive episode): odds ratios for females ranged between 1.49 and 1.80, and for the unemployed from 1.19 to 1.25. All types of depression produced a significant decrement in health status compared with no depression after controlling for demographic variables, income and country.

\section{Conclusions}

Subthreshold depressive disorders occur commonly all across the world and are associated with the same risk factors everywhere. They produce significant decrements in health and do not qualitatively differ from full-blown episodes of depression as currently defined, and lie on a continuum with more severe forms of depressive episodes but are distinct from normal mood changes.

\section{Declaration of interest}

None
Recent literature, in the context of the revision of classification systems such as the DSM-IV ${ }^{1}$ and the ICD-10, ${ }^{2}$ has increasingly addressed the issues around a dimensional $v$. a categorical approach to affective disorders. ${ }^{3}$ The idea of a continuum, embodied in the dimensional approach, is that depressive disorders are better conceptualised along a spectrum with increasing severity of symptoms and which may vary from nonspecific depressive symptoms (that do not amount to a disorder) to minor depression to major depression..$^{4-6}$

For subthreshold types of depression, different definitions based on the number of depressive symptoms, duration of symptoms, exclusion criteria and associated functional impairment have been proposed. ${ }^{7}$ Although nosological boundaries remain unclear, an operational definition for 'subsyndromal' depression (or subthreshold, used interchangeably in this paper) was introduced by Judd et al who defined the category subsyndromal symptomatic depression as 'any two or more simultaneous symptoms of depression, present for most or all of the time, at least two weeks in duration, associated with evidence of social dysfunction, occurring in individuals who do not meet criteria for diagnoses of minor depression, major depression, and/or dysthymia. ${ }^{8}$ The public health importance of subsyndromal depression has been highlighted with reported rates varying according to the definition used between 8.4 and $9.9 \%$ in community samples, or from 5 to $16 \%$ in primary care patients. ${ }^{8,9}$ The association with significant clinical and functioning impairment has also been pointed out ${ }^{10,11}$ along with increased use of health services, higher degree of morbidity and poorer social functioning and quality of life than those without depression. $^{12}$

Depressive symptoms, minor depression, dysthymia and major depression disorder have been suggested to represent a continuum of depressive symptom severity in unipolar major depressive disorder, each level of which is associated with a significant stepwise increment in psychosocial disability. ${ }^{5}$ The
ICD-10 diagnostic criteria for research classify subthreshold episodes in the category 'not otherwise specified' without specified diagnostic criteria, hence limiting its clinical utility and replicability. The lack of clear definitions means that the extent and nature of depressive symptoms that impact on peoples' lives in non-clinical settings cannot be measured in a comparable manner. In the present study, data from the World Health Survey, a cross-national general population survey of the World Health Organization (WHO) representing all regions of the world, were used to explore the impact that subsyndromal depression has on the overall health status in the general population and to test if subthreshold depression, although representing a distinct change from no depression, lies on a continuum with forms of depression above the threshold with no significant differences in characteristics except for severity.

\section{Method}

\section{Sample}

Countries in the World Health Survey were selected purposively to represent all regions of the world, with 29 countries from the European region, 18 from the African region, 7 from the Americas, 4 from the Eastern Mediterranean region, 5 from the Southeast Asia region and 5 from the Western Pacific region; a total of 68 countries. Of this total, 19 countries were classified in the high economic level group according to the World Bank list of economies, ${ }^{13} 12$ were in the upper-middle level, 16 in the lower-middle, and 21 in the low level. The countries represented in the survey programme reflect those countries that were willing and able to participate in the survey. Countries with samples that were nationally representative, probabilistically selected, and which had sampling weights information available were used in the analysis for this paper. All samples were probabilistically selected and were weighted in keeping with the design of each 
survey. To adjust for the population distribution as represented by the UN Statistical Division (http://unstats.un.org/unsd/ default.htm) and for non-response, post-stratification corrections were made to the sampling weights. ${ }^{14}$ In order to make valid comparisons across countries, both age and gender standardisation was carried out based on the WHO's World Standard Population ${ }^{15}$ and the gender distribution as represented by the UN Statistical Division. Informed consent was obtained from all respondents and the study was approved by the ethical review committees at each site. The individual response rate was $98.5 \%$ estimated across all the surveys.

The final sample was composed of 252503 people. However, 33242 were removed from these analyses because of missing data in the core items assessing the presence of depressive symptoms. These respondents also had missing data on one or more key sociodemographic variables. The respondents excluded from the survey were not different in terms of gender $(55.7 \% v .55 .8 \%$ of women in the included $v$. excluded respondents respectively, $P=0.660$ ); there were small differences in other sociodemographic variables: mean age of 41.0 (s.d.=16.6) v. 42.7 (s.d. = 17.1) years, $53.3 \%$ v. $60.8 \%$ in the proportion married and $5.65 \%$ v. $5.53 \%$ in the percentage of people divorced or separated; these differences are statistically significant because of the large sample sizes but are unlikely to have systematically biased the results. In the final sample, $55.7 \%$ were women, the mean age was 45.0 years (s.d $=63.0)$ and the mean years of formal education was 7.5 (s.d. $=5.2$ ); $60.5 \%$ of the respondents were married, $19.6 \%$ single and $8.9 \%$ widowed; $4.9 \%$ were unemployed (and looking for a job) at the time of the assessment.

\section{Measures}

All respondents were interviewed using the World Health Survey instrument that collected data on sociodemographic characteristics, household economic status based on a list of indicators (see below), lifetime diagnosis of depression, lifetime and current treatment for depression, and symptoms of depression in the past year.

\section{Assessment of depression symptoms}

Individual questions based on the World Mental Health Survey version of the Composite International Diagnostic Interview (CIDI) ${ }^{16}$ were included to assess the presence of depressive symptoms and length of duration over the past 12 months.

\section{Diagnostic categories}

All respondents were classified in four mutually exclusive diagnostic categories according to the presence or absence of depressive symptoms. All diagnoses were derived from 12-month prevalence data and were established according to the ICD-10 Diagnostic Criteria for Research (ICD-10-DCR). ${ }^{2}$ The groups were as follows.

(a) Depressive episode group: participants in this group endorsed at least four depressive symptoms lasting 2 weeks most of the day or all of the day. According to the ICD-10-DCR criterion $\mathrm{B}$, at least two of the following three symptoms needed to be present: depressed mood, loss of interest and fatigability.

(b) Brief episode group: participants in this group had an identical symptom profile to those in the depressive episode group but did not meet the duration criterion of 2 weeks.

(c) Subsyndromal depression group: participants in this group were those who endorsed at least one symptom from criterion $\mathrm{B}$ of the ICD-10-DCR and did not meet criteria for depressive episode as the total number of symptoms did not add to the minimum of four symptoms required by the ICD-10-DCR. The criteria of duration of at least 2 weeks and presence of symptoms during most of the day were required.

(d) No depressive disorders group: this group included respondents who did not meet either the symptomatic criteria or the duration or the persistence criteria for depressive disorders.

\section{Health status}

The measure of health status was based on 16 questions pertaining to difficulties in functioning grouped into eight health domains: vision, mobility, self-care, cognition, interpersonal activities, pain and discomfort, sleep and energy, and affect. For each question the responses were recorded on a five-point scale ranging from no difficulty or problem to extreme difficulty/ inability. These domains are included in many commonly used health outcome measures such as the Short Form-12 (SF-12), ${ }^{17}$ the Health Utilities Index Mark 3 (HUI-3) ${ }^{18}$ and the EuroQol (EQ-5D). ${ }^{19}$ A composite health status score was derived from the 16 self-reported health questions. Item response theory (IRT) was used to score the responses to the 16 self-reported health questions using a partial credit model that served to generate a composite health status score. ${ }^{20}$ An item calibration was obtained for each item. In order to determine how well each item contributed to common global health measurement, chi-squared fit statistics were calculated. The calibration for each of the 16 health items was taken into account and the raw scores were transformed through Rasch modelling into a continuous cardinal scale where a score of 0 represents worst health and a maximum score of 100 represents best health.

\section{Statistical analysis}

Weighted prevalence estimates were calculated for the four exclusive categories defined by the presence or absence of depressive symptoms as defined above. Demographic characteristics across the different subgroups of the population were calculated. A series of binary logistic regression analyses were then carried out, taking each subtype of depression $v$. the non-depressed group as the dependent variable and all demographic characteristics considered before as independent variables as dummy variables. Finally, a linear regression analysis was performed in order to test the effects of the subtype of depression on health, after controlling for several demographic variables included as dummies in the analysis. All analyses were carried out with STATA, version 10.0 for Windows Vista.

\section{Results}

Weighted age and gender standardised prevalence estimates for depressive episode, brief depressive episode, subsyndromal depression and no depression are shown in online Table DS1. Countries in online Table DS1 are grouped according to the World Bank categories of country income, and the global standardised prevalence for these categories are reported in Table 1. Sociodemographic characteristics of each group are shown in Table 2. The standardised pooled prevalence estimates were $7.38 \%$ for the depressive episode group, $3.01 \%$ for the brief episode group, $2.85 \%$ for the subsyndromal depression group and $13.2 \%$ for any type of depression. 


\begin{tabular}{|c|c|c|c|c|c|}
\hline \multirow[b]{2}{*}{ World Bank category } & \multirow[b]{2}{*}{$n$} & \multicolumn{4}{|c|}{ Prevalence estimates (s.e.) } \\
\hline & & $\begin{array}{l}\text { Non-depressed } \\
\text { group }\end{array}$ & $\begin{array}{c}\text { Subsyndromal } \\
\text { depression group }\end{array}$ & $\begin{array}{l}\text { Brief depressive } \\
\text { episode group }\end{array}$ & $\begin{array}{l}\text { Depressive episode } \\
\text { group }\end{array}$ \\
\hline High & 23174 & $86.8(0.2)$ & $3.4(0.1)$ & $3.5(0.1)$ & $6.3(0.2)$ \\
\hline Upper-middle & 64557 & $89.6(0.1)$ & $2.1(0.1)$ & $3.0(0.1)$ & $5.3(0.1)$ \\
\hline Lower-middle & 68483 & $88.7(0.1)$ & $1.9(0.1)$ & $3.0(0.1)$ & $6.4(0.1)$ \\
\hline Low & 96289 & $87.3(0.1)$ & $3.1(0.1)$ & $2.7(0.1)$ & $6.9(0.1)$ \\
\hline Total & 252503 & $86.8(0.2)$ & $2.8(0.1)$ & $3.0(0.1)$ & $7.4(0.2)$ \\
\hline
\end{tabular}

\begin{tabular}{|c|c|c|c|c|c|}
\hline Characteristic & $\begin{array}{c}\text { Depressive } \\
\text { episode group }\end{array}$ & $\begin{array}{l}\text { Brief depressive } \\
\text { episode group }\end{array}$ & $\begin{array}{c}\text { Subsyndromal } \\
\text { depression group }\end{array}$ & $\begin{array}{l}\text { Non-depressed } \\
\text { group }\end{array}$ & $P$ \\
\hline Sample size, $n(\%)$ & $15894(6.3)$ & $7546(3.0)$ & $6305(2.5)$ & $222758(88.2)$ & \\
\hline Prevalence estimates $^{\mathrm{a}}$ (95\% Cl) & $7.38(6.99-7.77)$ & $3.01(2.81-3.21)$ & $2.85(2.65-3.05)$ & $86.76(86.37-87.15)$ & \\
\hline Female: \% (s.e.) & $68.8(0.37)$ & $67.5(0.54)$ & $64.2(0.60)$ & $54.1(0.11)$ & $<0.001$ \\
\hline Age, years: mean (s.d.) & $46.5(17.7)$ & $40.9(16.8)$ & $46.3(17.9)$ & 40.5 (16.4) & $<0.001$ \\
\hline Marital status, \% (s.e.) & & & & & $<0.001$ \\
\hline Never married & $13.3(0.27)$ & $19.5(0.45)$ & $12.6(0.42)$ & $20.0(0.08)$ & \\
\hline Married & $54.5(0.39)$ & $53.4(0.57)$ & $60.6(0.61)$ & $61.5(0.10)$ & \\
\hline Separated & $4.3(0.16)$ & $3.9(0.22)$ & $3.0(0.21)$ & $2.3(0.03)$ & \\
\hline Divorced & $4.4(0.16)$ & $4.3(0.23)$ & $4.1(0.25)$ & $2.8(0.03)$ & \\
\hline Widowed & $18.0(0.30)$ & $11.6(0.37)$ & $14.7(0.44)$ & $7.9(0.06)$ & \\
\hline Cohabitating & $5.5(0.18)$ & $7.4(0.30)$ & $5.0(0.27)$ & $5.4(0.05)$ & \\
\hline Education, years: mean (s.d.) & $5.9(5.2)$ & $7.8(5.3)$ & $6.5(5.6)$ & $7.7(5.2)$ & $<0.001$ \\
\hline Income quintiles, \% (s.e.) & & & & & $<0.001$ \\
\hline Lowest quintile & $23.7(0.34)$ & $20.7(0.46)$ & $26.3(0.55)$ & $22.5(0.09)$ & \\
\hline 2nd quintile & $25.2(0.34)$ & $20.6(0.46)$ & $23.8(0.53)$ & $24.6(0.09)$ & \\
\hline 3rd quintile & $23.0(0.33)$ & $23.7(0.49)$ & $20.4(0.50)$ & $22.6(0.09)$ & \\
\hline 4th quintile & $17.4(0.30)$ & $20.0(0.46)$ & $14.9(0.45)$ & $17.8(0.08)$ & \\
\hline Highest quintile & $10.7(0.24)$ & $14.9(0.41)$ & $14.8(0.44)$ & $13.5(0.07)$ & \\
\hline Unemployed, \% (s.e.) & $5.2(0.17)$ & $6.4(0.28)$ & $4.4(0.26)$ & $5.2(0.05)$ & $<0.001$ \\
\hline
\end{tabular}

\section{Comparisons of predictors}

Table 3 shows the results from the final equation for the binary logistic regression separately for each subtype of depression (with the non-depressed group as the comparison category in all cases) with every demographic variable considered to influence the presence of depressive symptoms. Most of the odds ratios for the variables considered were highly significant and the pattern of the relationship between these variables and the specific condition was very similar across the different types of depression.

\section{Determinants of mean health score}

Linear regression was used to test the association between health status and type of depression and sociodemographic variables. The mean variance inflation factor $(\mathrm{VIF})=4.17$ suggests that multicollinearity is not a substantive problem in the data, allowing for meaningful interpretation of the results. Results are shown in Table 4 . The $R^{2}$ was 0.2738 and the adjusted $R^{2}$ was 0.2735 taking into account that the health status estimates were scored in a positive direction (the higher the score the better the health). The results indicate that women reported a worse health status than men. Increased age is associated with decreasing health status, as is being in the lower income quintiles and having a lower education status. An unmarried status is associated with better health compared with being divorced or widowed and with worse health compared with those married. Most importantly, all subtypes of depression are associated with worse health status compared with the non-depressed group, with no clear differences between the different subtypes. Given the variation across countries in the prevalence figures we tested these effects separately for the four World Bank categories. The main effect that all the subtypes studied were associated with worse health was confirmed across all country groups with minor differences in the effect of the specific covariates across countries (detailed results available upon request from the author). Figure 1 shows the kernel density function estimation for the health scores according to each type of depression severity. The distribution of the health status scores among the non-depressed group clearly differs from the density distribution in the rest of the groups indicating a clear separation in the threshold between the non-depressed group and all subtypes of depression. The distribution of the health status score in the pooled sample is also represented in Fig. 1. The mean score was 74.91 (s.d. $=14.87$, interquartile range $(\mathrm{IQR})=18.06)$. Figure 2 graphically shows a boxplot of the differences in health status scores in terms of the median score and IQR, across each of the different subtypes of depression confirming the separation across a threshold between the non-depressed group and all the subtypes of depression. 


\begin{tabular}{|c|c|c|c|}
\hline \multirow[b]{2}{*}{ Predictors } & \multicolumn{3}{|c|}{ Odds ratio (s.e.) } \\
\hline & Depressive episode group & Brief depressive episode group & Subsyndromal depression group \\
\hline Gender (reference category men) & $1.79 *(0.04)$ & $1.80 *(0.05)$ & $1.49 *(0.05)$ \\
\hline Age, years & $1.02 *(0.00)$ & $1.00(0.00)$ & $1.02 *(0.00)$ \\
\hline \multicolumn{4}{|l|}{ Marital status (reference category married) } \\
\hline Never married & $1.05(0.03)$ & $1.10 * * *(0.04)$ & $0.98(0.04)$ \\
\hline Separated & $1.78 *(0.08)$ & $1.50 *(0.10)$ & $1.32 *(0.11)$ \\
\hline Divorced & $1.71 *(0.08)$ & $1.37 *(0.09)$ & $1.35^{*}(0.10)$ \\
\hline Widowed & $1.50 *(0.04)$ & $1.42 *(0.07)$ & $1.18 *(0.06)$ \\
\hline Cohabitating & $1.10^{* \star *}(0.05)$ & $1.28^{*}(0.07)$ & $1.15^{* * \star}(0.08)$ \\
\hline Years of formal education & $0.96 *(0.00)$ & $1.00(0.00)$ & $0.98^{*}(0.00)$ \\
\hline \multicolumn{4}{|l|}{ Income quintiles (reference category highest) } \\
\hline Lowest quintile & $1.56 *(0.09)$ & $1.21 * *(0.09)$ & $1.28^{\star \star}(0.09)$ \\
\hline 2nd quintile & $1.49 *(0.07)$ & $1.11(0.08)$ & $1.19 * * *(0.09)$ \\
\hline 3rd quintile & $1.32 *(0.06)$ & $1.15^{\star \star \star}(0.07)$ & $1.10(0.08)$ \\
\hline 4th quintile & $1.21 *(0.05)$ & $1.09(0.06)$ & $1.10(0.07)$ \\
\hline Employment (reference employed) & $1.19 *(0.05)$ & $1.25 *(0.07)$ & $1.21 * *(0.07)$ \\
\hline Country (67 dummy variables, results not reported) & - & - & - \\
\hline
\end{tabular}

\begin{tabular}{|c|c|c|c|}
\hline Independent variables & Coefficient (s.e.) & $P$ & $\beta$ \\
\hline Gender (reference category men) & $-3.30(0.06)$ & $<0.001$ & -0.111 \\
\hline Age, years & $-0.29(0.00)$ & $<0.001$ & -0.324 \\
\hline \multicolumn{4}{|l|}{ Marital status (reference category married) } \\
\hline Never married & $-0.33(0.08)$ & $<0.001$ & -0.009 \\
\hline Separated & $-0.77(0.17)$ & $<0.001$ & -0.008 \\
\hline Divorced & $-0.35(0.16)$ & 0.029 & -0.004 \\
\hline Widowed & $-1.26(0.11)$ & $<0.001$ & -0.024 \\
\hline Cohabitating & $-0.39(0.13)$ & 0.002 & -0.006 \\
\hline Years of formal education & $0.16(0.01)$ & $<0.001$ & 0.056 \\
\hline \multicolumn{4}{|l|}{ Income quintiles (reference category highest) } \\
\hline 1st quintile & $-2.72(0.16)$ & 0.001 & -0.073 \\
\hline 2nd quintile & $-2.16(0.14)$ & $<0.001$ & -0.062 \\
\hline 3rd quintile & $-1.55(0.12)$ & $<0.001$ & -0.044 \\
\hline 4th quintile & $-0.90(0.11)$ & $<0.001$ & -0.024 \\
\hline Employment (reference employed) & $-0.23(0.12)$ & 0.069 & -0.003 \\
\hline \multicolumn{4}{|l|}{ Type of depression (reference non-clinical) } \\
\hline Subsyndromal & $-8.60(0.18)$ & $<0.001$ & -0.088 \\
\hline Brief episode & $-10.08(0.16)$ & $<0.001$ & -0.114 \\
\hline Depression & $-12.27(0.11)$ & $<0.001$ & -0.197 \\
\hline Country (67 dummy variables, results not reported) & - & - & - \\
\hline Constant & $94.98(0.44)$ & $<0.001$ & - \\
\hline
\end{tabular}

\section{Discussion \\ Main findings}

This study aimed to analyse the impact on health status of types of depression with different levels of symptomatic severity, as well as to check potential differences between these categories, in terms of prevalence and related sociodemographic factors. The study reveals that depressive disorders form a spectrum that ranges from fewer depressive symptoms to shorter durations to a full-blown episode as currently defined in the ICD-10-DCR. This spectrum of depressive disorders is common and affects over $13 \%$ of the population. As compared with those without depression, across the entire spectrum of depression assessed in the study, those with depression experience a significant decrement in their health status controlling for gender, age, marital status, income, years of education and country of residence. Decrements in health status, however, do not differ significantly between the different subtypes, although a linear decline occurs across the spectrum.

The main strength of this study lies in its generalisability given the large study population of nationally representative samples from a large number of countries, including all regions of the world and different levels of economic development. The pattern of the relationships and the size of the effects reported are hence likely to be robust. Although the impact of depression, even in subsyndromal presentations, has been largely reported in the literature, there was a marked lack of cross-cultural information and of studies with non-clinical samples from the general population. Thus, the worldwide character of our study provides a background for comparisons across countries, and could potentially help research on the boundaries of depression and its magnitude in both low- and middle-income countries and high-income countries. 

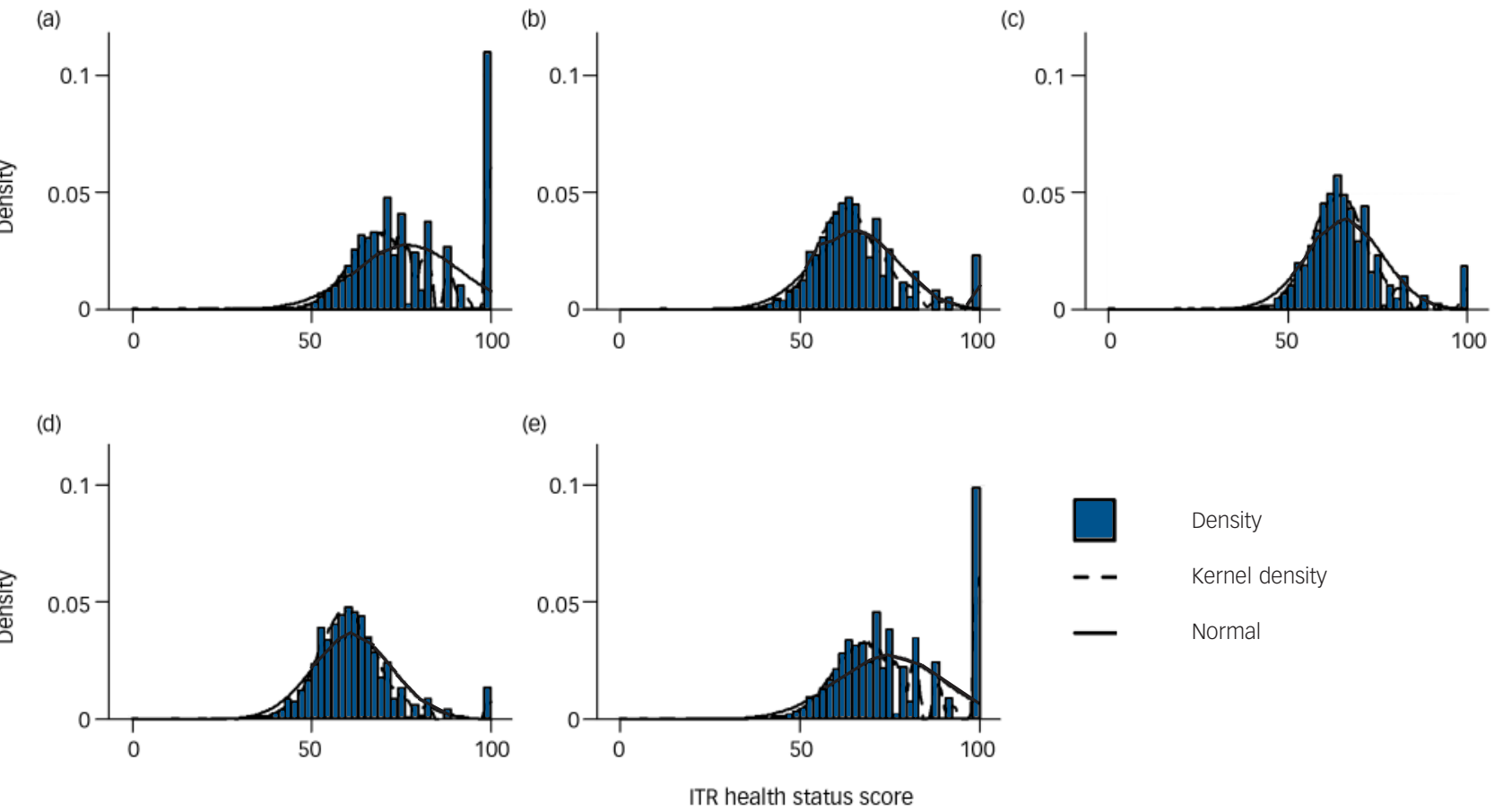

Fig. 1 Density distribution of impact health scores in the four groups. (a) Non-depressed group, (b) subsyndromal depression group, (c) brief episode depression group, (d) depressive episode group, and (e) total. IRT, item response theory.

Subsyndromal depression appears to be a significant problem in the general population across countries. The percentage of participants reporting subsyndromal depression was substantial, although slightly lower than reported in other population-based studies. For example, Rucci et $a l^{9}$ found a prevalence of $9.9 \%$ using ICD-10 criteria, although they did not require the presence of the duration criterion. Comparisons across studies remain limited because of the lack of consensus in the defining criteria for subthreshold depression.

The prevalence for the different types of depression varied markedly across countries, although in the analyses of the impact on health status we controlled for country and separate analyses of the impact in different levels of the World Bank classification did not indicate meaningful differences. Previous studies have also found marked differences in depression rates across countries ${ }^{21}$ that could not be attributed to a 'category fallacy, but to true differences in the prevalence. The instrument used can justify differences in prevalence rates in this study with those previously reported in the literature. For example, a recent study in China has found that more than $6 \%$ of people had mood disorders, ${ }^{22}$ whereas in our study we found a prevalence of $0.8 \%$ and the figure for China from the World Mental Health survey is $1.8 \%$ for 1 -year prevalence. ${ }^{23}$ Differences in diagnostic thresholds and in the interview procedures could explain the high rates in the Philips et al study as suggested by other authors. ${ }^{24}$ The exact method used to identify respondents in community samples will influence the prevalence of depression obtained. The questions we used have been used extensively in international applications of the CIDI that has been independently validated with clinical reappraisals. ${ }^{25}$

Results of the logistic regressions for each subtype of depression $v$. the non-depressed group pointed out a very similar pattern of predictors. The effect of each of the demographic variables suggested that the pattern of relationship between these sociodemographic characteristics and the three levels of severity of depression was comparable with no clear between-group differences.
All subtypes of depression produce significant decrements in health status. The impact of full-blown depressive episodes on health status has often been reported in the existing literature. ${ }^{10,14}$ The impact of less severe types of depression is more controversial in the literature. This study shows that subsyndromal depressive conditions clearly have an impact on health that is distinguishable from not having depression. Finally, the discontinuity in the impact between any type of depression and the non-depressed group suggests that the minimum depressive symptomatology as described in this study should merit attention from health services. These findings taken together support our hypothesis that although the group of depressive disorders thus defined are a distinctly identifiable entity, within the group they lie on a continuum of severity. Our study is limited by the fact that we did not assess other detailed symptoms of depression such as

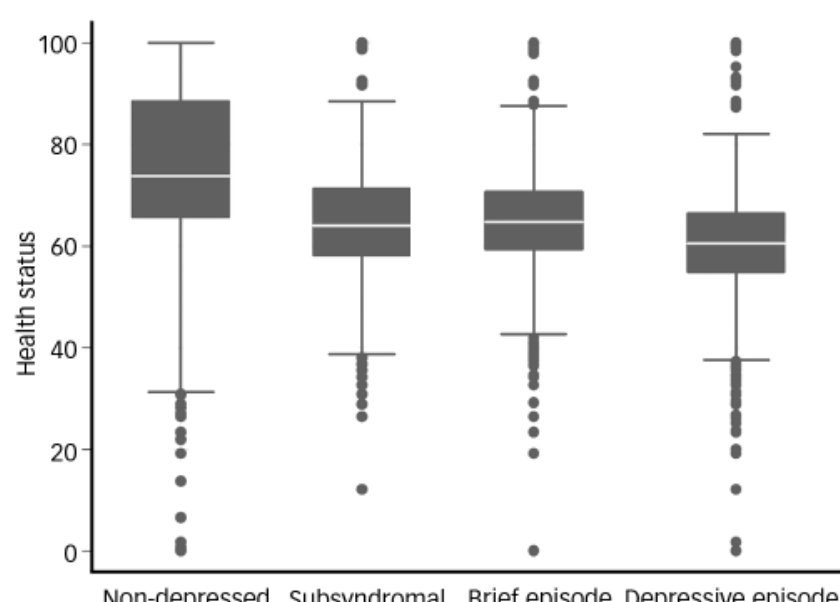

Fig. 2 Mean health score estimates of respondents according to group 
those for melancholia or the somatic syndrome as described in the ICD-10-DCR..$^{26,27}$ Hence, it is not possible to examine if such subtypes of depression are distinct and qualitatively different from the continuum assessed in our study.

The presence of one or more depressive symptoms among the core symptoms of depression seems to identify a group of individuals who are distinct from those with no core depressive symptoms suggesting this to be a more appropriate threshold for identifying clinically depressed individuals within a classificatory system such as the ICD, and questions the complete dimensional character of depression from 'normal' depressive symptoms through severe forms of depression widely reported in previous literature. ${ }^{6,28}$ Although the decrement associated with the symptoms of the depressive episode group appears to be greater than for the other subtypes of depression, all subtypes have significant and large effects on health status.

Other studies have suggested using a clinical significance criterion to define the cut-off for subthreshold depression to avoid pathologising human behaviour. However, these studies have also identified that those individuals who pass the threshold criteria have a distinct symptomatic profile. ${ }^{29}$ This is in support of our hypothesis that what matters is the defining of depressive disorders based on the presence of core depressive symptoms rather than on decrements in health with severity then being graded based on the number of symptoms. The gap between the non-depressed group and the subsyndromal depression group in our study questions the exact threshold of depression usually employed in the diagnostic criteria such as the ICD or the DSM. Regarding the discussion between categorical and dimensional approaches to depression, this gap suggests that if a dimension is assumed it is within the group of depressive disorders with a point of rarity between no depressive disorder and this group (i.e. in the step from non-depressed to subsyndromal). Both approaches would involve the identification of a threshold above which a person ought to be identified and treated given the impact of the symptoms on health status above such a threshold.

\section{Limitations}

Limitations of this work include the lack of questions about potential confounders and variables regarding the severity or disability associated with depressive symptoms such as the number and frequency of depressive episodes, episode length, age at onset or episode severity as defined by more extensive ratings of individual additional symptoms. Longitudinal studies are needed in order to analyse the natural evolution of these subclinical syndromes in the general population. Hence, it is not possible in this study to examine questions such as how common are subthreshold depressive disorders by themselves compared with being residual states of major depressive episodes or being characterological in nature. ${ }^{30}$ The cross-sectional nature of the study also means it is not possible to establish the direction of the causal link between depression and health status.

\section{Clinical implications}

The study has implications for both current approaches to the classification of depressive disorders, and by extension, their identification and management in primary care settings. Given that the presence of one or more persistent core depressive symptoms identifies individuals with significant disability, future revisions of the classification and research into biological and other correlates of depression ought to take into account the current ICD-10-DCR threshold of four symptoms. In primary care, healthcare providers need to be taught to identify individuals with these core symptoms in order to institute early interventions, both pharmacological and non-pharmacological, in these milder forms of depression that nonetheless remain significantly disabling. Preliminary studies suggest that subthreshold depressive disorders are a clinically relevant issue for primary care providers and with regular continued long-term relationships with patients it is possible to respond to people with these conditions. ${ }^{31}$ Also, quality improvement programmes for people with subthreshold depression suggest that comprehensive disease management strategies might be cost-effective in this population and comparable to other medical interventions. ${ }^{32} \mathrm{~A}$ recent metaanalysis of the diagnosis of depression in primary care across more than ten countries revealed that when general practitioners make a judgement that a patient is clinically depressed they are wrong four out of five times, but that they are very good at excluding depression; being correct 19 out of 20 times. ${ }^{33}$ However, one of the major challenges identified was the setting of thresholds for depression, as a third of clinicians rate their diagnostic decisions with regard to depression as being not definitive and a large number of errors occur with regard to the assessment of clinical significance. This has led to the suggestion to revise the nosology of mood disorders in the classification systems of the DSM and ICD. ${ }^{34}$ The challenge remains in identifying individuals who are close to the threshold - a problem of particular relevance in estimating population estimates of burden of disease and in developing strategies in primary care. ${ }^{35}$

In conclusion, subthreshold depressive disorders need to be subsumed within the current classificatory systems as being a part of core depressive episodes as long as key symptoms, that persist, are present. These key symptoms thus need to be differentially weighted as is implicit in current classificatory systems. The severity within the category of depressive episodes then needs to be defined based on the number of symptoms present. Given the disability that is associated with these conditions, strategies to extend and scale up care for people with these conditions using a stepped care approach needs to be developed and tested. ${ }^{36}$ These subsyndromal presentations of depression need to be distinguished from normal suffering and further studies are needed to examine the range of depressive symptoms, including the qualitative nature of the sadness itself, that can perhaps assist in defining these boundaries. Depression is affected by environmental and personal circumstances, but if a clearly identifiable set of symptoms have a real impact on health and functioning they ought to merit attention for intervention purposes.

José L. Ayuso-Mateos, MD, Roberto Nuevo, PhD, Department of Psychiatry, Hospital Universitario de la Princesa, Universidad Autonoma de Madrid and Instituto de Salud Carlos III, Centro de Investigación Biomédica en Red de Salud Mental, CIBERSAM, Spain; Emese Verdes, PhD, Nirmala Naidoo, MA, Somnath Chatterji, $M D$, Department of Health Statistics and Informatics, World Health Organization, Geneva, Switzerland

Correspondence: Somnath Chatterji, Department of Health Statistics and Informatics Systems, World Health Organization, Geneva 27, Switzerland. Email: chatterjis@who.int

First received 6 Aug 2009, final revision 31 Dec 2009, accepted 19 Jan 2010

\section{Funding}

Supported by the Instituto de Salud Carlos III, Centro de Investigación Biomédica en Red de Salud Mental, CIBERSAM Spain (www.cibersam.es).

\section{Acknowledgement}

The views expressed in this paper are those of the authors and do not necessarily represent the views or policies of the World Health Organization. 


\section{References}

1 American Psychiatric Association. Diagnostic and Statistical Manual of Mental Disorders (4th edn) (DSM-IV). APA, 1994.

2 World Health Organization. The ICD-10 Classification of Mental and Behavioural Disorders: Diagnostic Criteria for Research. WHO, 1993.

3 Kessing LV. Epidemiology of subtypes of depression. Acta Psychiatr Scand 2007; 433 (suppl): 85-9.

4 Angst J, Sellaro R, Merikangas KR. Depressive spectrum diagnoses. Compr Psychiatry 2000; 41 (suppl 1): 39-47.

5 Judd LL, Akiskal HS. Delineating the longitudinal structure of depressive illness: beyond clinical subtypes and duration thresholds. Pharmacopsychiatry 2000; 33: 3-7.

6 Andrews G, Brugha T, Thase ME, Duffy FF, Rucci P, Slade T. Dimensionality and the category of major depressive episode. Int J Methods Psychiatr Res 2007; 16 (suppl 1): S41-51.

7 Pincus HA, Davis WW, McQueen LE. 'Subthreshold' mental disorders. A review and synthesis of studies on minor depression and other 'brand names'. Br J Psychiatry 1999; 174: 288-96.

8 Judd LL, Rapaport MH, Paulus MP, Brown JL. Subsyndromal symptomatic depression: a new mood disorder? J Clin Psychiatry 1994; 55 (suppl): 18-28.

9 Rucci P, Gherardi S, Tansella M, Piccinelli M, Berardi D, Bisoffi G, et al. Subthreshold psychiatric disorders in primary care: prevalence and associated characteristics. J Affect Disord 2003; 76: 171-81.

10 da Silva Lima AF, de Almeida Fleck MP. Subsyndromal depression: an impact on quality of life? J Affect Disord 2007; 100: 163-9.

11 Rapaport MH, Judd LL. Minor depressive disorder and subsyndromal depressive symptoms: functional impairment and response to treatment. J Affect Disord 1998; 48: 227-32.

12 Goldney RD, Fisher $\mathrm{U}, \mathrm{Dal}$ GE, Taylor AW. Subsyndromal depression: prevalence, use of health services and quality of life in an Australian population. Soc Psychiatry Psychiatr Epidemiol 2004; 39: 293-8.

13 World Bank. World Bank List of Economies, 2007. World Bank, 2007 (http://www.dukeupress.edu/library/2009/world_bank_July_07.pdf).

14 Moussavi S, Chatterji S, Verdes E, Tandon A, Patel V, Ustun B. Depression, chronic diseases, and decrements in health: results from the World Health Surveys. Lancet 2007; 370: 851-8.

15 Ahmad OB, Boschi-Pint C, López AD, Murray CJL, Lozano R, Inoue M. Age Standardization of Rates: A New WHO Standard. GPE Discussion Paper Series. World Health Organization, 2001.

16 Kessler RC, Ustun TB. The World Mental Health (WMH) Survey Initiative Version of the World Health Organization (WHO) Composite Internationa Diagnostic Interview (CIDI). Int J Methods Psychiatr Res 2004; 13: 93-121.

17 Ware Jr J, Kosinski M, Keller SD. A 12-Item Short-Form Health Survey: construction of scales and preliminary tests of reliability and validity. Med Care 1996; 34: 220-33.

18 Feeny D, Furlong W, Boyle M, Torrance GQ. Multi-attribute health status classification systems. Health Utilities Index. Pharmacoeconomics 1995; 7: 490-502.
19 Kind P. The Euroqol instrument: an index of health-related quality of life. In Quality of Life and Pharmacoeconomics in Clinical Trials (ed B Spiker) 191-201. Lippincott-Raven Publishers, 1996.

20 Wilson $\mathrm{M}$, Allen DD, Li JC. Improving measurement in health education and health behavior research using item response modeling: comparison with the classical test theory approach. Health Educ Res 2006; 21 (suppl 1): i19-32.

21 Simon GE, Goldberg DP, Von KM, Ustun TB. Understanding cross-national differences in depression prevalence. Psychol Med 2002; 32: 585-94.

22 Phillips MR, Zhang J, Shi Q, Song Z, Ding Z, Pang S, et al. Prevalence, treatment, and associated disability of mental disorders in four provinces in China during 2001-05: an epidemiological survey. Lancet 2009; 373: 2041-53.

23 Lee S, Tsang A, Huang YQ, He YL, Liu ZR, Zhang MY, et al. The epidemiology of depression in metropolitan China. Psychol Med 2009; 39: 735-47.

24 Lee S. Mental illness in China. Lancet 2009; 374: 1063-4.

25 Haro JM, Arbabzadeh-Bouchez S, Brugha TS, de Girolamo G, Guyer ME, Jin R, et al. Concordance of the Composite International Diagnostic Interview Version 3.0 (CIDI 3.0) with standardized clinical assessments in the WHO World Mental Health surveys. Int J Methods Psychiatr Res 2006; 15: 167-80.

26 Parker G, Fletcher K, Hyett M, Hadzi-Pavlovic D, Barrett M, Synnott H. Measuring melancholia: the utility of a prototypic symptom approach. Psychol Med 2009; 39: 989-98.

27 Parker G. How should mood disorders be modelled? Aust N Z J Psychiatry 2008; 42: 841-50.

28 Ruscio J, Haslam M, Ruscio A. Applications of the taxometric methods. In Introduction to the Taxometric Method (eds J Ruscio, M Haslam, A Ruscio): 263-86. Erlbaum, 2006.

29 Baumeister H, Morar V. The impact of clinical significance criteria on subthreshold depression prevalence rates. Acta Psychiatr Scand 2008; 118: 443-50.

30 Spijker J, de Graaf R, Oldehinkel AJ, Nolen WA, Ormel J. Are the vulnerability effects of personality and psychosocial functioning on depression accounted for by subthreshold symptoms? Depress Anxiety 2007; 24: 472-8.

31 Backenstrass $M$, Joest $K$, Rosemann $T$, Szecsenyi J. The care of patients with subthreshold depression in primary care: is it all that bad? A qualitative study on the views of general practitioners and patients. BMC Health Serv Res 2007; 7: 190

32 Wells KB, Schoenbaum M, Duan N, Miranda J, Tang L, Sherbourne C. Cost-effectiveness of quality improvement programs for patients with subthreshold depression or depressive disorder. Psychiatr Serv 2007; 58 : 1269-78.

33 Mitchell AJ, Vaze A, Rao S. Clinical diagnosis of depression in primary care: a meta-analysis. Lancet 2009; 374: 609-19.

34 Tyrer $\mathrm{P}$. Are general practitioners really unable to diagnose depression? Lancet 2009; 374: 589-90.

35 Veerman JL, Dowrick C, Ayuso-Mateos JL, Dunn G, Barendregt JJ. Population prevalence of depression and mean Beck Depression Inventory score. Br J Psychiatry 2009; 195: 516-9.

36 World Health Organization. World Health Organization mhGAP: Mental Health Gap Action Programme. Scaling Up Care for Mental, Neurological and Substance Use Disorders. WHO, 2008. 